\title{
It's a Boy Thing: The Role of the Internet in Young People's Psychological Wellbeing
}

\author{
Lauren Donchi and Susan Moore \\ Swinburne University of Technology, Australia
}

\begin{abstract}
The aim of this study was to assess the relationship between psychological wellbeing and Internet use among adolescents, focussing not only on time spent on the Internet, but also on the relative strength/importance of both face-to-face and Internet friendship networks. A sample of 336 young people aged between 15 and 21 years from a secondary school and a university population were surveyed. Results indicated that females with more online friends were higher on selfesteem and lower on loneliness than females with fewer online friends, but the opposite was true for males. A higher number of online regular friendships seemed to militate against self-esteem and was related to greater loneliness for males. For face-to-face friendships, the effects on wellbeing were in the same direction for males and females, but stronger for males. Those with more face-to-face friendships were higher on self-esteem and less lonely. In addition, young men who rated their online friendship networks as very important were more likely to have lower self-esteem and to be lonely. Actual time spent on the Internet was not a predictor of wellbeing for either sex when online and offline friendship factors were included in the regression equation.
\end{abstract}

W ith 429 million people worldwide having access to the Internet (Nielson/ Netratings, 2001), adolescents today are growing up in a globally interactive world. In Australia, 37\% of all households currently have Internet access and this percentage is continuing to rise (Australian Bureau of Statistics, 2001). However, while the majority of Australians (61\%) have some access to the Internet (Barr, Knowles, \& Moore, 2003), the largest single grouping of users is teenage children (Aisbett, 2001). Males, particularly younger males, are more frequent users than females, although Odell, Korgen, Schumacher and Delucchi (2000) argue that the gender gap is closing quickly. Given these statistics, it would not be surprising to find that the Internet has a marked effect on social life. Is this effect beneficial or malign?

One way to assess the relationships between social wellbeing and Internet use among young people is to examine the role that online and offline (face-to-face) friendships play in the alleviation of loneliness and the maintenance or development of self-esteem. Are those with fewer, or weaker, face-to-face friendships more likely to resort to Internet relationships? While it is well known that friendship is important to wellbeing, is this importance specific to face-to-face friends? Can 
online relationships substitute for offline ones, or does time spent on the Internet in relationship development and maintenance have the effect of reducing face-toface interactions, with subsequent ill-effects?

Another variable of importance in examining wellbeing in Internet-use relationships is the actual time spent online. Longer amounts of time could be interpreted as relatively antisocial, and may reduce possibilities for social learning and social reinforcement in 'real-life' situations. On the other hand, if the time is spent engaged in Internet relationships, social learning and social rewards may still be available. Thus, in this study, we investigated the associations between time spent on the Internet (in different pursuits including personal communication, entertainment and information-seeking), number and importance of online and offline friendships, and social wellbeing.

This study focuses on Internet use and social relationships of young people in the 15 to 21 years age group, that is, the period of middle- to late-adolescence, and a time in which friendship and peer-group belongingness is particularly salient to psychosocial development. A central task of adolescence is the development of an identity - a realisation of who you are and how you fit into the surrounding social world (Kagan \& Gall, 1998). The peer group provides an important context for this pursuit of self-discovery and independence, as adolescents explore new ideas and different roles when they interact with friends. Accordingly, during the adolescent years there is an increase in the amount of time young people spend with their friends (Larson \& Richard, 1991). Peer interactions present opportunities for adolescents to develop the social competencies and social skills required for participation in adult society (Hartup, 1989). Research affirms that peer friendships are important for maintaining psychological health and that peer-relationship difficulties are likely to be a source of stress to young people that leads to feelings of loneliness (Demir \& Tarhan, 2001; Parkhurst \& Asher, 1992). Thus, peer relations play a significant role in promoting adolescent social-emotional development.

While adolescent social relations typically take place in face-to-face settings, the introduction of communication applications on the Internet (e.g., email, chatrooms, Usenet newsgroups), connecting users globally, has led to the suggestion that Internet networks may also function as important social networks for users (e.g., Garton, Haythornthwaite, \& Wellman, 1997; Wellman et al., 1996). Some support for this view is provided by Parks and Floyd (1996), who surveyed 176 regular contributors to Usenet newsgroups and found that nearly two-thirds of respondents had formed personal relationships with people they had met via an Internet newsgroup. Similarly, Parks and Roberts (1998) surveyed 235 participants in online text-based games and found that $94 \%$ had formed ongoing personal relationships with other players. Further, a study by the Pew Internet and American Life Project (2001) carried out telephone interviews with 754 Internet users between the ages of 12 and 17 and found that Internet communication was an essential feature of young people's social lives and had partially replaced face-to-face interactions. So while the Internet enables people to form online social networks, whether these online friendships can provide a substitute for face-to-face friendships in assisting development towards social maturity and psychological wellbeing is an open question.

The measurement of social networks generally involves asking people to estimate 'the number of friends' they have. It is unlikely that this simplistic measure captures important qualities such as the strength, perceived importance and utility of friendship networks. A Social Network Scale (Moody, 2001) was recently developed that 
incorporates this psychological content of friendship into the measurement of social networks. Such a measure has the potential to be more reliable and valid as an assessment of friendship importance and will be used in the present study, in addition to assessing total number of friends. The scale includes a measurement of both the importance of face-to-face friendship and online friendship.

Disturbing signs that the Internet fosters loneliness in users first emerged in a longitudinal study conducted by Kraut and colleagues (Kraut et al., 1998; Kraut \& Mukopadhyay, 1999) during 1995-96. They studied the impact of Internet use on 169 people in 73 families in the United States who had never before used the Internet. Each family was provided with a free home computer and Internet access in exchange for allowing the researchers to automatically track their Internet usage (e.g., hours online) for 12 to 24 months and for completing surveys periodically that measured, among other things, loneliness, assessed by 3 items from the UCLA Loneliness Scale (Version 2; Russell, Peplau, \& Cutrona, 1980). In general, participants who were lonely at the beginning of the study were not any more likely to use the Internet than those who were not. However, two years later, although the Internet was used extensively for communication, the researchers found that after controlling for initial-outcome variables, greater use of the Internet was associated with increased loneliness. They also found that teenagers used the Internet for more hours than adults and increases in Internet use were associated with larger increases in loneliness for teenagers than for adults. These findings were somewhat controversial, and the study was criticised for methodological reasons (small sample; no control group without access to the Internet). Recently, Kraut et al. (2002) conducted a follow-up study of 208 of the remaining participants from the original sample and found that the negative relationship between greater use of the Internet and loneliness had dissipated.

Since the publication of Kraut et al.'s (1998) original study that claimed 'using the Internet adversely affects psychological wellbeing' (p. 1028), social scientists have shown renewed interest in the Internet. However, much of the available research on Internet use and psychological wellbeing has produced mixed results.

Some research has substantiated claims that Internet use is associated with reduced psychological wellbeing. For example, Armstrong, Phillips and Saling (2000) examined Internet use and self-esteem levels of 50 participants recruited through the World Wide Web (WWW). Internet use was assessed by multiplechoice questions addressing time spent on the Internet per week and self-esteem was measured using the Coopersmith Self-esteem Inventory (Robinson, Shaver, Wrightsman, \& Andrews, 1991). The results indicated that more time spent on the Internet was associated with lower self-esteem.

A recent longitudinal study conducted by Shaw and Gant (2002) investigated the Internet use, loneliness and self-esteem levels of 40 students at a university in the United States. Five structured chat sessions on the Internet between anonymous participant dyads were conducted over a 4 to 8 week period and all participants were administered the UCLA Loneliness Scale (Version 2; Russell et al., 1980) and the Texas Social Behaviour Inventory (Helmreich \& Stapp, 1974) at three different intervals to assess changes over time in loneliness and self-esteem respectively. They found that over the course of the study, during which subjects chatted anonymously on the Internet, participants' loneliness decreased and self-esteem increased.

Other research has shed doubt on the association between Internet use and psychological wellbeing. Gross, Juvonen and Gable (2002) found that time online was 
not associated with loneliness. They surveyed 130 adolescents between the ages of 11 and 13 years at a secondary school in the United States. Internet use was assessed by participants' estimation of how much time they spent using the Internet on a typical day and 9 items from the UCLA Loneliness Scale (Version 4; Russell, 1996) were used to measure loneliness. In addition to their follow-up study, Kraut and colleagues (2002) conducted a second longitudinal study during 1998-99 to further examine the relationship between Internet use and psychological wellbeing. They studied 406 new computer and television purchasers in 216 households in the United States. Surveys were administered three times during the study to measure self-reported Internet use, loneliness, self-esteem and personality. This time the researchers found no overall relationship between Internet use and loneliness or self-esteem. However, they found that Internet use was associated with better outcomes for extroverts (i.e., decreased loneliness and increased self-esteem) and worse outcomes for introverts (i.e., increased loneliness and decreased self-esteem). Hence in this study, individual characteristics served as important moderating variables between Internet use and psychological wellbeing. Waestlund, Norlander and Archer (2001) replicated the Kraut et al. (1998) Internet paradox study, and although they found that younger individuals tended to use the Internet more and experienced lower wellbeing than other groups, there was not a causal relationship between Internet use and wellbeing. In sum, while much research has studied the relationship between Internet use and psychological wellbeing, the available data is equivocal.

One reason for the mixed findings regarding Internet use and loneliness may be that while evidence points to the importance of employing a multidimensional concept of loneliness (e.g., Jong-Gierveld \& Raadschelders, 1982), there is little available research which links more complex conceptions of loneliness to Internet use. Most studies have employed the UCLA Loneliness Scale (Russell, 1996; Russell et al., 1980), which has come to be viewed as the standard scale to assess loneliness, measuring it as a global construct. One exception was Weiss (1973), who distinguished between emotional loneliness and social loneliness. Emotional loneliness is characterised by a feeling of abandonment, emptiness and apprehension due to the absence of a close, intimate attachment. Social loneliness refers to the feeling of boredom and marginality due to the lack of belonging to a social network or community. Weiss argues that relief from emotional loneliness requires the formation of an attachment relationship that promotes a sense of emotional security, whereas remediation from social loneliness requires being accepted as a member of a friendship network that provides a sense of social integration.

The association between Internet use and Weiss's (1973) bimodal theory of loneliness was examined by Moody (2001), who compared 166 university students' self-reported Internet use to their social and emotional loneliness and to their friendship networks both on the Internet and on a face-to-face basis. Moody developed the Social Network Scale to assess the latter. His findings revealed that while students who spent more time on the Internet communicating with friends were likely to have higher rates of emotional loneliness, they were less likely to experience social loneliness than those who spent less time on the Internet communicating with friends. Moody concluded that the psychological effects of Internet use are more complex than previous studies have indicated. His findings suggest that by limiting the face-to-face component of social interaction, emotional loneliness might occur despite high Internet use, providing some individuals with a sense of social integration and thus lowered social loneliness. 
Following Moody's (2001) lead, the present study employed Weiss's (1973) distinction between emotional and social loneliness in studying the associations between Internet use, social networks and psychological wellbeing. Furthermore, in keeping with previous research, global loneliness (as measured by the UCLA scale) and self-esteem were also used as measures of psychological wellbeing. The study distinguished between time spent on different activities on the Internet, and used measures of social networks which included, but were not limited to, number of friends (as discussed above). In short, this study examined the relationships between wellbeing, time spent on the Internet, and social networks, including online and offline (face-to-face) networks. Patterns of relationships were examined separately for the sexes because of previous research suggesting differences in the ways young men and young women use the Internet, even though differences in the amount of time spent on the Internet by males and females are closing (Odell et al., 2000).

\section{Method}

\section{Participants}

There were 336 participants, aged 15 to 21 years in the sample (114 males and 222 females). This included 110 school-based volunteers aged between 15 and 18 years from a regional secondary school and 226 university-based volunteers aged between 17 and 21 years from two campuses (one regional and one city-based) of a university in Melbourne, Australia. Twenty-six students were in Year 10 (8\%), 56 in Year $11(17 \%), 28$ in Year 12 (8\%), 183 in their first year of university (55\%), 14 in their second year (4\%) and 29 students were completing their third year $(9 \%)$. The mean age of the secondary school sample was $16.16(S D=0.77)$ and the mean age of the university sample was $18.55(S D=1.12)$.

\section{Materials}

The questionnaire consisted of sections designed to measure demographic variables (gender, age, education level), Internet use, social networks, loneliness and self-esteem.

Measuring Internet use. In order to assess the amount of time young people spend on the Internet on an average day, respondents were presented with a list of Internet activities. Thirteen of the activities related to three categories of Internet use: interpersonal communication ( 4 items; e.g., 'visiting chat rooms'), entertainment (5 items; e.g., 'searching for things of personal interest') and information (4 items; e.g., 'finding articles and references'). For each Internet activity, participants were asked to indicate in minutes the time spent on each activity 'on an average day'. Total scores for each activity type were calculated by summing minutes across the items. The total time-scale had an alpha reliability of .77.

Measuring social networks. Respondents' use of the Internet and face-to-face relations for communicating with friends was measured using the 12-item Social Network Scale (Moody, 2001). The scale consists of two 6-item subscales: Internet social network importance (e.g., 'I converse more easily with people when I am on the Net') and face-to-face social network importance (e.g., 'I like to have a lot of friends whom I see regularly'). Respondents were asked to indicate how well each item described them on a 5-point Likert scale ranging from 1 (not like me) to 5 (a lot like me). In the current study, the Internet social network importance subscale 
had a high Cronbach's alpha of .87 and the face-to-face social network importance subscale had a low alpha of .54.

In order to assess the number of friends young people regularly communicate with on the Internet and on a face-to-face basis, participants were asked to answer two questions: 'How many friends do you talk to regularly on the Internet?' and 'How many friends do you talk to regularly on a face-to-face basis?'

Measuring loneliness. The UCLA Loneliness Scale was used to measure loneliness conceptualised as a global, unidimensional construct (Version 3; Russell, 1996). The revised UCLA Loneliness Scale (Russell, Peplau, \& Cutrona, 1980) has been shown to have strong internal consistency, reliability and validity (Paloutzian \& Janigian, 1989; Robinson, Shaver, Wrightsman, \& Andrews, 1991). The 20-item scale has 10 descriptive feelings of loneliness and 10 descriptive feelings of satisfaction with social relationships. Participants respond on a 4-point scale to the 20 statements indicating whether each statement is characteristic of their feelings $(3=$ often, 2 = sometimes, 1 = rarely, 0 = never). The test is scored in a range from 0 (lowest loneliness) to 60 (highest loneliness). The scale was initially designed from accounts of social and emotional experiences of lonely people.

Wittenberg's (1986) 10-item Emotional and Social Loneliness Scale (Robinson, Shaver, Wrightsman, \& Andrews, 1991) was used to measure loneliness conceptualised as a multidimensional construct. The scale comprises two 5 -item subscales that distinguish between emotional loneliness (e.g., 'I don't have a special love relationship') and social loneliness (e.g., 'Mostly, everyone around me seems like a stranger'). Respondents were asked to indicate how frequently they felt the way described by each item on a 5-point Likert scale ranging from 1 (never) to 5 (very often). In the current study, the UCLA Loneliness Scale had a high Cronbach's alpha of .90 and the emotional and social loneliness subscales had moderate-tohigh Cronbach's alphas of .71 and .83 respectively.

Measuring self-esteem. The measure used to obtain an assessment of self-esteem was Form A of the 16-item Texas Social Behaviour Inventory (TSBI-Form A; Helmreich \& Stapp, 1974). All of the items related to aspects of social interaction (e.g., 'I cannot seem to get others to notice me'). Respondents were asked to indicate how characteristic each item was of them on a 5-point Likert scale ranging from 0 (not at all characteristic of me) to 4 (very much characteristic of me). In the present study, a high Cronbach's alpha of .85 was obtained for the TSBI-Form A.

\section{Procedure}

Permission to conduct the study was obtained from the Human Research Ethics Committee at the relevant university and the deputy principal of the secondary school where the study was also being conducted. For the secondary school sample, 6 classes comprising 25 students from years 10 to 12 were invited to participate in the study. Teachers were informed by the deputy principal of the purpose and procedures of the study and asked to distribute parental permission forms to students and then 'take home' questionnaires one week later. Seven parents did not consent for their child to participate in the study. Teachers were asked to remind their homeroom class to return the questionnaires to a designated box at the reception office before the Easter break, which gave them two weeks. For the university sample, 300 students from introductory psychology and business classes were invited to participate in the study by completing a questionnaire in their own time. 
Questionnaires were distributed at the beginning of lectures. Introductory psychology students received partial course credit for completion of the questionnaire. Students were instructed to return questionnaires to a designated box at the university or via mail. Response rates of $77 \%$ and $75 \%$ were obtained from the secondary school and university groups respectively.

\section{Results}

Measures of Internet use for personal communication, entertainment and information-gathering on an average day (measured in minutes) were screened for outliers. There were 8 extreme outliers for both personal communication and entertainment and 3 for information-gathering. Each of the outliers was reduced to three standard deviations above the mean number of minutes for the sample. Similarly, the estimates of number of online friends included 6 extreme outliers which were reduced to three standard deviations above the sample mean. There were no extreme outliers among any of the other measures, and all measures were approximately normally distributed.

\section{Gender differences in Internet Use}

Males and females spent similar lengths of time on the Internet on an average day engaged in personal communication: female mean - 65.4 minutes, male mean 68.7 minutes; and information-seeking: female mean -56.5 minutes, male mean 59.1 minutes. However, males spent significantly longer using the Internet for entertainment on an average day, in fact, about twice as much time as females: female mean - 63.9 minutes, male mean -121.6 minutes; $F(1,335)=25.75, p<.001$. In addition, males said they had more regular Internet friends than females: male mean -14.0 Internet friends, female mean -11.2 Internet friends; $F(1,335)=18.04, p$ $<.001$. For face-to-face regular friendships the trend was reversed, with females indicating more friendships: female mean face-to-face friendships - 21.6, male mean face-to-face friendships $-20.0 ; F(1,335)=10.89 ; p<.01$. The sexes did not differ on the importance they attached to either Internet or face-to-face friendships.

\section{Relationships between Online and Face-to-face Friendships}

Table 1 shows the correlations between number and perceived importance of onand offline friendships for males and females separately. The numbers of friends onand offline were positively associated for both sexes; the more friends in one domain, the more in the other (they may indeed be an overlapping set). An interesting gender difference occurred for the scales measuring perceived importance of the two domains; for females these two scales were unrelated, suggesting that online and offline networks were not developed at the expense of one another. For males, these two scales were negatively associated, suggesting that the young men in this study tended to emphasise one domain over the other.

\section{Network Group Differences on Wellbeing}

The number of regular face-to-face friends (face-to-face friends) and number of regularly-communicated-with online friends (online friends) were divided at their respective medians into high and low face-to-face and high and low online friendship groups. A four-way multivariate analysis of variance was conducted with gender (male, female), education level (school, university), face-to-face friendship group (high, low) and online friendship group (high, low) as the independent variables. 
TABLE 1

Relationships Between Online and Face-to-face Friendships (correlations for males above diagonal; for females below diagonal)

\begin{tabular}{lcccc}
\hline & $\begin{array}{c}N \text { Regular } \\
\text { face-to-face } \\
\text { friends }\end{array}$ & $\begin{array}{c}\text { N Regular } \\
\text { online } \\
\text { friends }\end{array}$ & $\begin{array}{c}\text { Face-to-face } \\
\text { network } \\
\text { importance }\end{array}$ & $\begin{array}{c}\text { Online } \\
\text { network } \\
\text { importance }\end{array}$ \\
\hline $\begin{array}{l}N \text { regular face-to-face friends } \\
N \text { regular online friends }\end{array}$ & 1.0 & $.31^{* *}$ & $.35^{* * *}$ & -.06 \\
$\begin{array}{l}\text { Face-to-face network } \\
\text { importance }\end{array}$ & $.41^{* *}$ & 1.0 & .06 & $.49^{* * *}$ \\
$\begin{array}{l}\text { Online network importance } \\
\text { im }\end{array}$ & .03 & $.15^{* * *}$ & 1.0 & $-.35^{* * *}$ \\
\end{tabular}

Note: ${ }^{*} p<.05,{ }^{* * *} p<.001, N=$ number

The dependent variables were the four measures of wellbeing: general loneliness (UCLA loneliness score), social loneliness, emotional loneliness and self-esteem.

The main effects of gender, $F(4,317)=8.01, p<.001$, and face-to-face friendship group, $F(4,317)=6.01, p<.001$, were significant; other main effects did not show significant group differences. Significant interactions were gender-by-onlinefriendship group, $F(4,317)=3.21, p<.05$, and gender-by-face-to-face-friendship group, $F(4,317)=2.97, p<.05$. These were the only significant interactions.

Univariate ANOVAS pinpointed the particular dependent variables for which these significant effects were present. Males were significantly more socially lonely than females: male mean - 10.86; female mean - 9.66; $F(1,320)=10.51$, $p<$ .001 ; and males were also significantly more emotionally lonely than females: male mean -12.87 , female mean $-10.91 ; F(1,320)=15.91, p<.001$. The trends for the males in the sample to have lower self-esteem and score higher on the UCLA loneliness scale than females were not statistically significant.

Not surprisingly, face-to-face friendship group was also related to the wellbeing measures. Specifically, those with more face-to-face friends had higher self-esteem than those in the low face-to-face friendship group: mean high face-to-face group - 42.22; mean low group $-37.31 ; F(1,320)=19.29, p<.001$. The high friendship group was also less socially lonely: mean high group - 9.03; mean low group $-10.78 ; F(1,320)=16.24, p<.001$; and less generally lonely on the UCLA scale than the low face-to-face friendship group: mean high group - 38.00; mean low group - 42.26; $F(1,320)=13.71, p<.001$.

The interpretation of these main effects needs to be modified by the significant univariate interactions. There were gender-by-friendship group interactions for both online and face-to-face friendship groups, which are shown in Tables 2 and 3. Table 2 shows that females with more online friends were higher on self-esteem and lower on loneliness than females with fewer online friends, but that the opposite was true for males. Higher numbers of online regular friendships seemed to militate against self-esteem and be related to greater loneliness for males. These effects were significant for 3 of the 4 wellbeing measures.

For face-to-face friendships, the effects on wellbeing were in the same direction for males and females, but they were stronger for males. Table 3 shows that those with more face-to-face friendships were higher on self-esteem and less lonely, with males 
TABLE 2

Gender-by-online-friendship-group Interaction on Wellbeing

\begin{tabular}{lccccc}
\hline & \multicolumn{2}{c}{ Males } & \multicolumn{2}{c}{ Females } & $\begin{array}{c}\text { Interaction } \\
F(1,320)\end{array}$ \\
\hline & $\begin{array}{l}\text { High online } \\
\text { friendships }\end{array}$ & $\begin{array}{c}\text { Low online } \\
\text { friendships }\end{array}$ & $\begin{array}{c}\text { High online } \\
\text { friendships }\end{array}$ & $\begin{array}{c}\text { Low online } \\
\text { friendships }\end{array}$ & \\
\hline Self-esteem & 37.95 & 39.14 & 41.92 & 38.56 & $4.22^{*}$ \\
Social loneliness & 11.02 & 10.76 & 8.62 & 10.15 & $6.90^{* *}$ \\
Emotional loneliness & 13.89 & 12.24 & 10.49 & 11.11 & $6.45^{*}$ \\
UCLA loneliness & 40.93 & 41.21 & 37.81 & 41.35 & $\mathrm{~ns}$ \\
\hline
\end{tabular}

Note: ${ }^{*} p<.05 ;{ }^{*} p<.01 ; \mathrm{ns}=$ not significant

showing greater extremes of loneliness and low self-esteem than females, and wellbeing as more strongly associated with face-to-face friendships for males than for females.

\section{Predicting Wellbeing from Number of Friends (On- and Offline), Social Network Importance (On- and Offline) and Time Spent on the Internet}

Regressions were conducted (separately for males and females) to assess whether the set of variables including number of online and face-to-face friends, perceived importance of online and face-to-face networks and time spent on the Internet predicted wellbeing (self-esteem and 3 measures of loneliness). None of the potential predictor variables were correlated at greater than .6, so that multicollinearity was not indicated. Correlations (available from the second author) showed a pattern for girls of significant positive correlations between wellbeing and face-to-face friendship indicators, and weak or nonsignificant correlations between wellbeing and online friendship indicators. There were no significant correlations between time spent on the Internet and wellbeing for girls. For boys, the correlations between wellbeing and face-to-face friendship indicators were significant and positive and between wellbeing and both time spent on the Internet and online friendship indicators were significant and negative. Table 4 shows the results of the regressions.

\section{TABLE 3}

Gender-by-face-to-face-friendship Interaction on Wellbeing

\begin{tabular}{lccccc}
\hline & \multicolumn{2}{c}{ Males } & \multicolumn{2}{c}{ Females } & $\begin{array}{c}\text { Interaction } \\
F(1,320)\end{array}$ \\
\hline & $\begin{array}{c}\text { High } \\
\text { face-to-face } \\
\text { friendships }\end{array}$ & $\begin{array}{c}\text { Low } \\
\text { face-to-face } \\
\text { friendships }\end{array}$ & $\begin{array}{c}\text { High } \\
\text { face-to-face } \\
\text { friendships }\end{array}$ & $\begin{array}{c}\text { Low } \\
\text { face-to-face } \\
\text { friendships }\end{array}$ & \\
\hline Self-esteem & 43.15 & 35.55 & 41.73 & 38.20 & $5.96^{*}$ \\
Social loneliness & 9.21 & 12.01 & 8.93 & 10.15 & $8.95^{* *}$ \\
Emotional loneliness & 12.02 & 13.48 & 11.13 & 10.76 & $4.69^{*}$ \\
UCLA loneliness & 37.13 & 43.90 & 38.46 & 41.42 & $4.40^{*}$ \\
\hline
\end{tabular}

Note: ${ }^{*} p<.05 ;{ }^{*} p<.01$ 
Predicting Wellbeing from Internet Use, Online and Face-to-face Friendships

\begin{tabular}{|c|c|c|c|c|c|c|c|c|}
\hline & & $\mathrm{Ma}$ & & & & Fema & ales & \\
\hline & & Beta w & eights & & & Beta w & eights & \\
\hline & UCLA & $\begin{array}{l}\text { Social } \\
\text { loneliness }\end{array}$ & $\begin{array}{l}\text { Emotional } \\
\text { loneliness }\end{array}$ & $\begin{array}{l}\text { Self- } \\
\text { esteem }\end{array}$ & UCLA & $\begin{array}{c}\text { Social } \\
\text { loneliness }\end{array}$ & $\begin{array}{l}\text { Emotional } \\
\text { loneliness }\end{array}$ & $\begin{array}{c}\text { Self- } \\
\text { esteem }\end{array}$ \\
\hline $\begin{array}{l}\text { No. face-to-face } \\
\text { friends }\end{array}$ & $-.21^{*}$ & $-.25^{* *}$ & -.05 & $.30^{* *}$ & $-.16^{*}$ & -.13 & .05 & $.16^{*}$ \\
\hline $\begin{array}{l}\text { No. online } \\
\text { friends }\end{array}$ & $-.25^{*}$ & -.14 & -.02 & .06 & -.02 & -.06 & -.04 & .01 \\
\hline $\begin{array}{l}\text { Importance } \\
\text { face-to-face } \\
\text { network }\end{array}$ & $-.24^{*}$ & $-.38^{* * *}$ & -.15 & $.34^{* * *}$ & $-.40^{* * *}$ & $-.37^{* * *}$ & $-.27^{* * *}$ & $.41^{* * *}$ \\
\hline $\begin{array}{l}\text { Importance } \\
\text { online network }\end{array}$ & $.34^{* *}$ & $.34^{* *}$ & $.31^{*}$ & $-.24^{*}$ & .12 & .10 & .14 & -.11 \\
\hline $\begin{array}{l}\text { Time online } \\
\text { (communication) }\end{array}$ & n) 10 & -.05 & .08 & .01 & -.08 & -.05 & -.04 & .06 \\
\hline $\begin{array}{l}\text { Time online } \\
\text { (entertainment) }\end{array}$ & .01 & -.01 & -.10 & -.12 & -.03 & -.11 & .00 & .05 \\
\hline $\begin{array}{l}\text { Time online } \\
\text { (information) }\end{array}$ & -.05 & .00 & -.06 & .07 & .00 & .05 & -.10 & .07 \\
\hline$F$ & $8.46^{* * *}$ & $13.81^{* * *}$ & $2.95^{* *}$ & $10.70^{* * *}$ & $9.98^{* * *}$ & $8.56^{* * *}$ & $3.19^{* *}$ & $10.54^{* * *}$ \\
\hline$d f$ & 7,106 & 7,106 & 7,106 & 7,106 & 7,214 & 7,214 & 7,214 & 7,214 \\
\hline R-square & .358 & .477 & .163 & .414 & .246 & .219 & .095 & .256 \\
\hline
\end{tabular}

Note: ${ }^{*} p<.05 ;{ }^{* *} p<.01 ; * * * p<.001$.

The regressions show a similar pattern of findings to the MANOVA, in the sense that the results for males suggest a greater implication of Internet use in loneliness and lower self-esteem. While the importance associated with face-to-face friendships and, to some extent, the number of face-to-face friends were the strongest predictors of loneliness and self-esteem, online relationship activity was also consistently associated with wellbeing for males, but in a negative direction. In other words, young men who rated their online friendship networks as very important were more likely to have lower self-esteem and to be lonely. None of the measures of time spent online (for communication, entertainment or information-related activities) were significant predictors of wellbeing.

\section{Discussion}

The present study supported previous research suggesting that young males would spend more time on the Internet on an average day than young females (Kraut \& Mukopadhyay, 1999; Odell et al., 2000; Waestlund et al., 2001). Both sexes indicated that they spent large amounts of time with this medium, three hours per day for girls and four for boys. While these times may have been overestimated due to the form of measurement used (assessing minutes per average day across several categories of activity), they do suggest some cause for concern. The gender gap had closed for the 
Internet activities of personal communication and information-seeking, but was still very much in evidence for Internet entertainment, an activity on which boys spent about two hours per day - twice as long as the girls. In addition, boys had more Internet friends and fewer face-to-face friends than girls, although the total friendship numbers were equal. Boys who ascribed high importance to their Internet friends tended to estimate their face-to-face networks as less important, while girls rated the importance of their Internet and face-to-face friendships similarly. The picture that emerges is of young people spending long hours at the computer, with boys in particular limiting their time for face-to-face interactions and, to some extent, discounting these. Time available for offline activities is thus reduced, particularly for boys. How do these findings relate to wellbeing?

Young people reported that the number of face-to-face friendships were clearly related to wellbeing, with more friends associated with higher self-esteem and lower social and general loneliness. These effects were stronger for boys, indicating that offline friends were particularly important as markers of wellbeing for them. In addition, while online friendships were associated with better wellbeing for girls, the opposite was true for boys. Higher numbers of regular online friendships amongst boys were related to lower self-esteem and greater loneliness. In the regressions, offline friendship number and perceived importance positively predicted wellbeing for both sexes, while online friendship number and importance negatively predicted wellbeing for boys only. These effects of friendship patterns swamped any relationships between wellbeing and time spent online.

Thus, the answer to the question of whether online social interactions can substitute for (or enhance) offline face-to-face friendships for young people during adolescence and early adulthood appears to be a definite 'no' for boys. There is a great deal of evidence that peer relations play an important role in promoting adolescent and youth social-emotional development, act as a buffer against loneliness and enhance self-esteem (e.g., Demir \& Tarhan, 2001; Parkhurst \& Asher, 1992). This study suggests a need for young men to experience a significant proportion of these peer relationships in the real-world domain. Those young men who strongly emphasise the importance of their online relationships may be cutting off options for psychosocial development through the give and take of face-to-face friendships. This may be a result of lack of social confidence and poor social skills leading to avoidance of real-world friendships with all their difficulties. Or it may be that the nature of Internet relationships (e.g., possibilities for anonymity and role-playing, reduced need to 'work at' friendships) can undermine skills needed in face-to-face relationships. Or, more simply, online friendships may reduce time available for offline friendships which appear to have a greater potential to relate positively to wellbeing. Kraut and colleagues (1998) speculated that negative effects of Internet use could result from both the displacement of social activities and of strong ties. According to this view, the time an individual spends online might interrupt or replace time they had previously spent engaged in real-life social activities. Furthermore, by using the Internet, an individual may be substituting their better real-life relationships or 'strong ties', which are thought to lead to better psychological outcomes, for artificial online relationships or 'weak ties'.

Girls, on the other hand, seem to have developed mechanisms by which their online activity does not interfere with offline friendships, and may even enhance it. For girls, more friendships either on- or offline related to positive indicators of wellbeing. This may relate in part to the fact that girls spend less time on the Internet alto- 
gether. In addition, when they do access the Internet, around one-third of this time is devoted to personal communication activities, some of which may involve relating to friends who are substantially of the face-to-face type. Boys, on the other hand, spend only about one-quarter of their time in such activities, preferring to engage in Internet entertainment, games and so on, which have a greater potential to be socially isolating.

It has been suggested that the lack of clarity in the literature to date regarding the association between wellbeing and Internet use may relate to issues surrounding the measurement of wellbeing (Moody, 2001). We used 4 measures and, in particular, were able to test out Moody's (2001) idea that time spent on the Internet communicating with friends would be related to higher emotional, but not higher social, loneliness. This was not the case. In fact, all wellbeing measures were negatively related to Internet focus (time spent on the Internet, Internet friendships, and their perceived importance) for boys. For girls, the relationships between Internet activity and measures of loneliness were weakly negative or nonexistent. Thus boys appear to be disadvantaged both socially and emotionally by their reliance on Internet friendships, while social and emotional advantage is associated with online and offline friendships for girls, and offline friendships for both sexes. The lack of distinction between results for social and emotional measures in this study suggests a more pervasive effect of the Internet than was postulated by Moody, although the reasons are unclear and require further research.

The controversy about whether high levels of Internet use directly lead to reduced wellbeing among young people has not been resolved by this study because its crosssectional nature did not allow for the imputation of causality (Kraut et al., 2002; Waestlund et al., 2001). Some light has been shed, however, on the controversy about whether such an association exists (e.g., Armstrong et al., 2000; Gross et al., 2002). By assessing wellbeing multidimensionally, using measures of offline as well as online social activity, measuring not only time spent on the Internet but types of activities undertaken, and analysing data separately for the sexes, we have been able to clarify to some extent the nature of the relationships. Why the association between reduced wellbeing and Internet activities occurred only for boys is not, however, clear and would be a profitable topic for further research. It may relate to the different ways girls and boys conduct friendships, with girls' more intimate friendship styles allowing for the forging of stronger alliances than boys, whose friendship styles tend to be more activity-oriented (Moore \& Boldero, 1991). It may relate to the fact that the boys in our sample were more socially and emotionally lonely than the girls, regardless of Internet use, although the interactions between friendship types (Internet, face-to-face) and gender exacerbated this loneliness difference. A longitudinal study that included baseline measures of social wellbeing and involved more detailed analyses of Internet activity (including antisocial and well as social uses of the Internet) would be of value in unravelling these findings.

\section{References}

Aisbett, K. (2001). The Internet at home: A report on Internet use in the home. Australian Broadcasting Authority. Retrieved July 20, 2002, from http://www.aba.gov.au/internet/research/home/pdfrtf/ Internet AtHome.pdf

Armstrong, L., Phillips, J.G., \& Saling, L.L. (2000). Potential determinants of heavier Internet usage. International Journal of Human-Computer Studies, 53, 537-550.

Australian Bureau of Statistics (2001). Use of the Internet by householders, Australia: Catalogue No. 8147.0, Canberra: Author. 
Barr, T., Knowles, A., \& Moore, S. (2003).Trust comes in many guises: Australians and Internet transactions. Proceedings of 2003 Annual Smart Internet Technology Conference Australian Technology Park. Sydney, Australia.

Demir, A., \& Tarhan, N. (2001). Loneliness and social dissatisfaction in Turkish adolescents. Journal of Psychology, 135, 113-124.

Garton, L., Haythornthwaite, C., \& Wellman, B. (1997). Studying online social networks. Journal of Computer-Mediated Communication, 3. Retrieved March 21, 2002, from http://www.ascusc. $\mathrm{org} / \mathrm{jcmc} / \mathrm{vol} 3 /$ issue1/garton.html

Gross, E.F., Juvonen, J., \& Gable, S.L. (2002). Internet use and wellbeing in adolescence. Journal of Social Issues, 58, 75-91.

Hartup, W.W. (1989). Social relationships and their developmental significance. American Psychologist, 44, 120-126.

Helmreich, R., \& Stapp, J. (1974). Short forms of the Texas Social Behaviour Inventory (TSBI), an objective measure of self-esteem. Bulletin of the Psychonomic Society, 4, 473-475.

Jong-Gierveld, J.D., \& Raadschelders, J. (1982). Types of loneliness. In L.A. Peplau \& D. Perlman (Eds.), Loneliness: A sourcebook of current theory, research and therapy (pp. 105-119). New York: Wiley.

Kagan, J., \& Gall, S.B. (Eds.) (1998). Gale encyclopaedia of childhood and adolescence. London: Gale.

Kraut, R., Kiesler, S., Boneva, B., Cummings, J., Helgeson, V., \& Crawford, A. (2002). Internet paradox revisited. Journal of Social Issues, 58, 49-74.

Kraut, R., \& Mukopadhyay, T. (1999). Information and communication: Alternative uses of the Internet in households. Information Systems Research, 10, 287-304.

Kraut, R., Patterson, M., Lundmark, V., Kiesler, S., Mukopadhyay, T., \& Scherlis, W. (1998). Internet paradox: A social technology that reduces social involvement and psychological well-being? American Psychologist, 53, 1017-1031.

Larson, R., \& Richards, M.H. (1991). Daily companionship in late childhood and early adolescence: Changing developmental contexts. Child Development, 62, 284-300.

Moody, E.J. (2001). Internet use and its relationship to loneliness. CyberPsychology E Behaviour, 4 , $393-401$.

Moore, S.M., \& Boldero, J. (1991). Psychosocial development and friendship functions in young Australian adults. Sex Roles, 25, 521-536.

Nielsen/Netratings. (2001). 429 million people worldwide have Internet access according to Nielsen/Netratings. Retrieved August 9, 2002, from http:// www.nielsennetratings.com/pr/pr _010611_2.pdf

Odell, P., Korgen, K., Schumacher, P., \& Delucchi, M. (2000). Internet use among female and male college students. CyberPsychology $\mathcal{E}$ Behaviour 3, 855-862.

Paloutzian, R. \& Janigian, A., (1989). Models and methods in loneliness research: Their status and direction. In M. Hojat, \& R. Crandall, (Eds.), Loneliness: Theory, research and applications (pp. 31-36). Newberry Park, CA: Sage.

Parkhurst, J.T., \& Asher, S.R. (1992). Peer rejection in middle school: Subgroup differences in behaviour, loneliness, and interpersonal concerns. Developmental Psychology, 28, 231-241.

Parks, M.R., \& Floyd, K. (1996). Making friends in cyberspace. Journal of Communication, 46. Retrieved March 20, 2002, from http://www.ascusc.org/jcmc/vol1/issue4/parks.html

Parks, M.R., \& Roberts, L.D. (1998). 'Making MOOsic': The development of personal relationships online and a comparison to their off-line counterparts. Journal of Social $\mathcal{E}$ Personal Relationships, 15, 517-538.

Pew Internet \& American Life Project. (2001). Teenage life online: The rise of the instant-message generation and the Internet's impact on friendships and family relationships. Retrieved August 20, 2002, from http://www.pewinternet.org/reports/pdfs/PIP_Teens_Report.pdf

Robinson, J.P., Shaver, P.R., Wrightsman, L.S., \& Andrews, F.M. (1991). Measures of personality and social psychological attitudes. San Diego, CA: Academic Press. 
Russell, D. (1996). The UCLA Loneliness Scale (Version 3): Reliability, validity and factor structure. Journal of Personality Assessment, 66, 20-40.

Russell, D., Peplau, L.A., \& Cutrona, C.E. (1980). The revised UCLA Loneliness Scale: Concurrent and discriminant validity evidence. Journal of Personality and Social Psychology, 39, 472-480.

Shaw, L.H., \& Gant, L.M. (2002). In defense of the Internet: The relationship between Internet communication and depression, loneliness, self-esteem, and perceived social support. CyberPsychology $\mathbb{E}$ Behavior, 5, 157-171.

Waestlund, E., Norlander, T, \& Archer, T. (2001). Internet blues revisited: replication and extension of an Internet paradox study. CyberPsychology $\mathcal{E}$ Behavior, 4, 385-391.

Weiss, R.S. (1973). Loneliness: The experience of emotional and social isolation. Boston, MA: The MIT Press.

Wellman, B., Salaff, J., Dimitrova, D., Garton, L., Gulia, M., \& Haythornthwaite, C. (1996). Computer networks as social networks: Collaborative work, telework, and virtual community. Annual Review of Sociology, 22, 213-238.

Wittenberg, M.T. (1991). Emotional versus social loneliness scales. In J.P. Robinson, P.R. Shaver, L.S. Wrightsman, \& F.M. Andrews (Eds.). Measures of personality and social psychological attitudes. San Diego, CA: Academic Press. 